\title{
НАТАЛЬЯ ВОЛОДИНА
}

Череповецкий государственный университет

Гуманитарный институт

Кафедра отечественной филологии

и прикладных коммуникаций

162612 Череповец

Советский пр., 8 A

rusfilolog@chsu.ru

\section{ДВОЙНИК Ф. М. ДОСТОЕВСКОГО И ДВОЙНИК Н. Д. АХШАРУМОВА: ПРОБЛЕМА ЛИТЕРАТУРНЫХ СВЯЗЕЙ}

\author{
THE DOUBLE OF FYODOR DOSTOYEVSKY \\ AND THE DOUBLE OF NIKOLAI AKHSHARUMOV: \\ THE PROBLEM OF LITERARY CONNECTIONS
}

В статье рассматриваются историко-литературные и интертекстуальные связи повести Ф. М. Достоевского Двойник и повести Н. Д. Ахшарумова с аналогичным названием. Как показывает проведенные исследование, писателей сближает доминанта психологического анализа, тема двойничества и топос Петербурга. Однако как сами герои, так и их двойники, отношения между ними у Достоевского и Ахшарумова являются прямо противоположными. Это свидетельствует о сложных законах литературной эволюции, включающей в себя не только момент влияния предшественника, но и полемику с ним.

Ключевые слова: Литературное влияние, проблема двойничества, петербургский текст.

The article is devoted to the historical, literary and intertextual connections between Dostoyevsky's novella The Double and Nikolai Akhsharumov's novella of the same title. The research indicates that the two writers' texts are linked by the dominant of psychological analysis, the theme of duality and the topos of St. Petersburg. However, the protagonists themselves, their doubles and the relationships between them are diametrically opposite in the works of Dostoevsky

\footnotetext{
${ }^{1}$ Работа выполнена при поддержке РГНФ (проект № 15-04-00491): Неисследованные «имена» в русском литературном процессе второй половины XIX века: Н. Д. Ахшарумов как прозаик и литературный критик.
} 
and Akhsharumov. This demonstrates the complex laws of literary evolution, which encompass not only the influence of a predecessor, but also taking issue with him.

Keywords: literary influence, the double (Doppelganger), 'Petersburg text'.

Исследователи считают повесть Н. Д. Ахшарумова Двойник подражанием Двойнику Ф. М. Достоевского ${ }^{2}$. Повесть Достоевского впервые была опубликована в 1846 г., в «Отечественных записках». Позднее, в 1866 г., Достоевский переработал ее и включил в трехтомное собрание сочинений. Кроме того, в том жегоду она вышла отдельным изданием. Ахшарумов напечатал Двойник в 1850 г. («Отечественные записки» 1850, № 3), под псевдонимом Н. Чернов, так что он мог ориентироваться только на журнальный вариант повести Достоевского. Достоевский заметил повесть Ахшарумова, ибо в письме брату, М. М. Достоевскому от 22 февраля 1854 года он задает вопрос: «Кто такой Чернов, написавший Двойник в 50 году?» ${ }^{3}$. Никакой оценки повести он не дает, так что об его впечатлении от прочитанного судить сложно. Характер отношений этих произведений можно выявить только при их сопоставительном анализе (ранее не предпринимавшемся).

Если устанавливать параллели произведения Ахшарумова с Двойником Достоевского, то это, прежде всего, повторяющееся название, которым Ахшарумов, скорее всего, сам подчеркивал внутреннюю связь его произведения с повестью Достоевского, тем более, что она была опубликована в том же журнале и с небольшим временным интервалом. Тем не менее, говорить о подражании Ахшарумова повести Достоевского можно весьма условно, тем более, что Двойник - раннее произведение Достоевского, которое критика, да и сам автор оценили не очень высоко ${ }^{4}$, за исключением В. Г. Белинского и В. Н. Майкова. Повесть Ахшарумова критика, похоже, вообще почти не заметила. Можно сослаться на короткое замечание А. В. Дружинина в Письмах иногороднего подписчика:

Так вот по каким причинам я люблю труды молодых нувеллистов и почему начал читать Двойника г. Чернова. Но, не найдя в этой повести и следов чего-нибудь юношеского, я ее

\footnotetext{
${ }^{2}$ См. об этом: О. Е. Майорова, Ахшарумов Н. Д., [в:] Русские писатели. 1800-1917. Биографический словарь, гл. ред. П. А. Николаев, Москва: Советская энциклопедия 1989, т. 1, с. 129; Г. М. Фридлендер, Двойник. Примечания, [в:] Ф. М. Достоевский, Полное собрание сочинений: в 30-ти тm., Ленинград: Наука 1985, т. 26, с. 229.

${ }^{3}$ Ф. М. Достоевский, Письма, [в:] он же, Полное собрание сочинений..., т. 26, с. 229.

${ }^{4}$ См. об этом: Г. М. Фридлендер, Двойник. Примечания, [в:] Ф. М. Достоевский, Полное собрание сочинений..., т. 1, с. 442-443, 446.
} 
оставил и тем, может быть, лишил себя удовольствия - об этом судить не могу. Повесть как повесть, и, может быть, при конце она довольно занимательна 5 .

Подражание (если не иметь в виду стилизацию) чаще всего связано с творческой незрелостью, периодом ученичества либо несамостоятельностью писателя; и тогда это факт, который стараются скрыть. Сознательная и подчеркнутая отсылка к другому тексту может рассматриваться в совершенно другой системе литературных координат: как диалог с ним, как полемика, влияние и т.д. Скорее всего, здесь следует говорить о литературном влиянии, испытанном Ахшарумовым, причем, не только Достоевского, но и в целом литературной традиции, связанной с изображением двойников. В русской литературе это, конечно, А. Погорельский, в известной мере - Нос Н. В. Гоголя. В повести Ахшарумова можно увидеть и другие литературные связи, прежде всего, с темой сумасшествия, нередко граничащей с мотивом двойничества: Записками сумасшедмего Н. В. Гоголя. Кроме того, у Ахшарумова есть элемент фантастического, который опять-таки можно обнаружить в предшествующий литературный период. Так, фамилия Лугиных, возможно, является интертекстуальной отсылкой к повести Лермонтова Штосс. Учитывая это, рассмотрим, какие именно (кроме названия и жанра) элементы повести Ахшарумова можно рассматривать в связи с Двойником Достоевского.

В обоих произведениях действие происходит в Петербурге. Все исследователи «петербургского текста» пишут о миражной, фантасмагорической природе этого города ${ }^{6}$, в котором фантастические происшествия (в данном случае - появление фантома, двойника) воспринимаются как вполне возможные. Встреча героя с двойником и у Достоевского, и у Ахшарумова возникает в похожей ситуации: на улице, причем, в одном и том же районе Петербурга: это Фонтанка, Аничков мост, Литейная. Герои Достоевского и Ахшарумова живут недалеко друг от друга: Голядкин - в Шестилавочной улице, Алексей Петрович - на Малой Морской. И хотя появление двойника перед Голядкиным происходит в ноябре, а в повести Ахшарумова летом, и в том, и в другом случае оно сопровождается ужасной погодой: дождем, ветром, слякотью. При этом топос Петербурга занимает у Достоевского гораздо большее место, чем в повести Ахшарумова.

${ }^{5}$ А. В. Дружинин, Письма иногороднего подписчика в редакиию «Современника» о русской журналистике (XII), «Современник» 1850, отд. VI, с. 192.

${ }^{6} \mathrm{Cм}$. об этом: В. Н. Топоров, Петербург и петербургский текст русской литератуpbl, [в:] он же, Миф. Ритуал. Символ. Образ: Исследования в области мифопоэтического: Избранное, Москва: изд группа «Прогресс» - «Культура» 1995, с. 259-367; Ю. М. Лотман, Символика Петербурга и проблемы семиотики города, [в:] он же, Избранные статьи, т. 2, Таллин: Александра 1992. 
И у Достоевского, и у Ахшарумова есть указания на психическое нездоровье героя, причем, у Ахшарумова куда более очевидные. Голядкин бывает у врача, но характер его болезни остается неясным, ибо во время их встреч говорит, в основном, Голядкин, а в его несвязных, витиеватых речах (свойственная ему манера говорить) трудно увидеть какой-либо смысл. О болезни Голядкина можно догадываться не только по его визитам к врачу, но и странному в глазах других поведению. Вся история с двойником заканчивается для него, очевидно, сумасшедшим домом. Не случайно доктор Крестьян Иванович в эпилоге кажется ему исчадием ада:

Несчастный господин Голядкин-старший бросил свой последний взгляд на всех и на всё и, дрожа, как котенок, которого окатили холодной водой, - если позволят сравнение, - влез в карету; за ним тотчас же сел и Крестьян Иванович. Карета захлопнулась; послышался удар кнута по лошадям, лошади рванули экипаж с места... все ринулось вслед за господином Голядкиным. [...] Он впал наконец в забытье... Когда же очнулся, то увидел, что лошади несут его по какой-то ему незнакомой дороге. Направо и налево чернелись леса; было глухо и пусто. Вдруг он обмер: два огненные глаза смотрели на него в темноте, и зловещею, адскою радостию блестели эти два глаза. Это не Крестьян Иванович! Кто это? Или это он? Он! Это Крестьян Иванович, но только не прежний, это другой Крестьян Иванович! Это ужасный Крестьян Иванович!.. Крестьян Иванович, я... я, кажется, ничего. Крестьян Иванович, - начал было робко и трепеща наш герой, желая хоть сколько-нибудь покорностию и смирением умилосердить ужасного Крестьяна Ивановича. - Ви получаит казенный квартир, с дровами, с лихт и с прислугой, чего ви недостоин, - строго и ужасно, как приговор, прозвучал ответ Крестьяна Ивановича.

Герой наш вскрикнул и схватил себя за голову. Увы! он это давно уже предчувствовал! ${ }^{7}$

Гоголевские реминисценции, восходящие к Записками сумастедшего, придают трагическое звучание финалу произведения.

Повесть Ахшарумова написана в форме дневника главного героя (Алексея Петровича); и то, что происходит с ним, он сам воспринимает как болезнь. Именно так называется первая часть повести. Название второй Кризис, третьей - Ампутащия (имеется в виду переносное значение этого слова). Алексей Петрович прячет дневник, ибо боится, что кто-то, случайно прочтя его записки, примет его за сумасшедшего. Форма повествования от первого лица предполагает самораскрытие героя, и в повести Ахшарумова, действительно, доминирует психологический анализ. Одно из главных свойств Алексея Петровича - склонность к рефлексии, которая постепенно принимает болезненный характер, и он сам это осознает. В одной из первых записей Алексей Петрович отмечает: «Я начинаю думать, что я решительно болен» ${ }^{8}$, «лекарства не помогают; болезнь в душе и с каждым днем идет все

\footnotetext{
${ }^{7}$ Ф. М. Достоевский, Двойник, [в:] он же, Полное собрание сочинений..., т. 1, с. 229.

${ }^{8}$ Н. Д. Ахшарумов, Двойник, «Отечественные записки» 1850, № 3, с. 12.
} 
хуже. Не знаю, есть ли на свете что-нибудь мучительнее такого ужасного разлада с самим собою...»". В эпилоге повести доктор Борис Карлович Мориц подтверждает, что у Алексея Петровича было душевное заболевание.

Роль доктора в повести Ахшарумова гораздо значительнее, чем у Достоевского. Крестьян Иванович просто дает Голядкину какие-то лекарства, пытаясь уменьшить его болезненное состояние, а в итоге, очевидно, отвозит его в больницу. Лечение Бориса Карловича Морица усугубляет болезнь Алексея Петровича, а сам врач играет едва ли не дьявольскую роль в его судьбе. В его портрете герою видится что-то бесовское: «Я поглядел ему в глаза. Они были черные, большие, глубоко вдавшиеся, и сверкали ярко под густыми, сдвинутыми бровями» ${ }^{10},-$ а смех доктора кажется Алексею Петровичу зловещим. Сам кабинет Морица, наполненный какими-то приспособлениями и машинами, скелетами людей и животных, чучелами птиц и зверей, «скорченными фигурами в спирте» ${ }^{11}$, вызывает у Алексея Петровича чувство «невольного отвращения». Наконец, он с ужасом воспринимает методы, к которым прибегает доктор: магнетизм и гальванический эксперимент: «Черт возьми! - подумал я, содрогаясь при мысли об этой дьявольской системе лечения» ${ }^{12}$. Суть метода доктора Морица состоит в том, что он пытается раздвоенность сознания героя довести до максимального предела, максимального напряжения, вслед за которым, по его логике, должно наступить облегчение. Делает это он с помощью гальванического устройства - «вольтова столба».

Как объясняет доктор, здесь нет ничего опасного, ибо речь идет не о физическом теле человека, но его душе, «принципе недействительном, нераздробляемом!» ${ }^{13}$. Однако в результате этого опыта в жизни Алексея Петровича происходят разительные перемены. Появление двойника до этого было только намечено в сознании героя. Он видит во сне, как внутри его мозга «две маленькие фигурки... махали руками и спорили горячо» ${ }^{14}$. После эксперимента Морица двойник занимает место рядом с ним.

Двойник Алексея Петровича принципиально отличается от Голядкина-младшего, как и разительно не похожи сами герои. Голядкин немолодой и невзрачный человек: его «подслеповатая и довольно оплешивевшая фигура была именно такого незначительного свойства, что с первого взгляда не останавливала на себе решительно ничьего исключительного внимания...» ${ }^{15}$. Он робок, косноязычен, вместе с тем не лишен амбиций. Восп-

\footnotetext{
9 Там же, с. 13.

${ }^{10}$ Там же, с. 18.

11 Там же, с. 23.

12 Там же, с. 20.

13 Там же.

14 Там же, с. 13.

${ }^{15}$ Ф. М. Достоевский, Двойник..., с. 110.
} 
ринимая себя «маленьким человеком» ${ }^{16}$, Голядкин настаивает на преимуществах этого положения: «я даже горжусь тем, что не большой человек, а маленький $\rangle^{17}$. Объясняя причины помешательства героя, Белинский впервые сказал о психологии подсознания человека, утрачивающего собственную идентичность:

Г. Голядкин - один из тех обидчивых, помешанных на амбиции людей, которые так часто встречаются в низших и средних слоях нашего общества. Ему все кажется, что его обижают и словами, и взглядами, и жестами, что против него всюду составляются интриги, ведутся подкопы. Это тем смешнее, что он ни состоянием, ни чином, ни местом, ни умом, ни способностями решительно не может ни в ком возбудить к себе зависти ${ }^{18}$.

В. Майков обратил внимание на социальные причины сумасшествия Голядкина - чувство своей социальной незащищенности - и вновь отметил мастерство психологического анализа писателя: «Двойник раскрывает перед нами анатомию души, гибнущей от сознания разрозненности частных интересов ${ }^{19}$. Все эти идеи позднее получат развитие в работах специалистов, занимающихся творчеством Достоевского ${ }^{20}$. Особое объяснение мотивов сумасшествия Голядкина предложил М. М. Бахтин - сквозь призму его концепции диалогического слова Достоевского. Интрига повести, как показывает ученый, основана на попытке Голядкина, «в виду полного непризнания его личности другими, заменить себе самому другого» ${ }^{21}$ и соответственно «развертывается в пределах самосознания Голядкина» ${ }^{22}$. Этот иной, согласно логике Бахтина, возникает из тех внутренних голосов, которое присутствуют в сознании Голядкина, вытесняя один другого.

Основная сфера жизни Голядкина, изображенная в повести Достоевского, - это его служба в департаменте (он титулярный советник), отношения с чиновниками. Внутренний мир героя предельно ограничен; лишен какого-либо духовного содержания; а его рефлексия связана исключительно с попыткой сохранить свое положение в департаменте и свою репутацию в глазах начальства от посягательств двойника. Голядкин борется со своим

16 Там же, с. 117.

17 Там же.

${ }^{18}$ В. Г. Белинский, Петербургский сборник, [в:] он же, Полное собрание сочинений: в 13-ти тm., Москва: Художественная литература 1958, т. 9, с. 563-564.

${ }^{19}$ В. Н. Майков, Нечто о русской литературе в 1846 году, [в:] он же, Литературная критика, Ленинград: Художественная литература 1985, с. 182.

${ }^{20}$ См. об этом: Г. М. Фридлендер, Двойник. Примечания..., т. 1, с. 442-443, 446; И. И. Евлампиев, Повесть «Двойник» и метафизика «двойничества» в творчестве Ф. М. Достоевского, «Соловьевские исследования» 2010, вып. (2) 26; В. С. Нечаева, Ранний Достоевский. 18211849, Москва: Наука 1979, с. 153-160 и др.

${ }^{21}$ М. М. Бахтин, Проблемы поэтики Достоевского, Москва: Советская Россия 1979, c. 250 .

22 Там же, с. 249. 
двойником именно потому, что он кажется ему более успешным, в результате чего и занимает его место. Голядкин-старший внешне не отличается от своего двойника - Голядкина-младшего: «такого же роста, такого же склада, так же одетый, с такой же лысиной» ${ }^{23}$, - однако двойник Голядкина оказывается еще примитивнее, чем он сам, это его «худшее» я. Он более ловок и красноречив, угодлив и пронырлив, а потому пользуется большим расположением начальства. Стереотип поведения Голядкина-младшего, в разных вариантах повторяющийся в повести, выглядит следующим образом:

[...] с свойственною ему наглостью осмотрелся кругом, посеменил окончательно, вероятно, чтобы оставить выгодное по себе впечатление, - около чиновников, сказал словцо одному, почтительно полизался с третьим, адресовал улыбку четвертому, дал руку пятому и весело юркнул вниз по лестнице ${ }^{24}$.

У Достоевского постоянно обнажена дискурсивная природа слова. Авторская характеристика, включающая в себя несобственно-прямую речь главного героя, носит откровенно пародийный характер.

Герой Ахшарумова совершенно другой тип человека. У Алексея Петровича отсутствует ощущение своей ущербности, которые подсознательно свойственно Голядкину. Он достаточно молод (ему около тридцати лет) и, очевидно, привлекателен внешне. У Алексея Петровича иной социальный статус, хотя он тоже, скорее всего, чиновник средней руки. Ахшарумов почти не говорит о служебной деятельности персонажа, представляя Алексея Петровича, в основном, в частной жизни. Если в Двойнике Достоевского история несостоявшегося сватовства Голядкина к Кларе Олсуфьевне носит характер квазиинтриги, имеет трагикомическое содержание, то в повести Ахшарумова есть любовные сюжеты, любовные истории. Одна из них в прошлом, связанная с бедной девушкой, Верой; другая в настоящем - взаимоотношения Алексея Петровича с Софьей Лугиной, его будущей женой.

Алексей Петрович образованный и творческий человек, наделенный развитым сознанием, чувством собственного достоинства и совестливостью. Рефлексия героя - это, прежде всего, самоанализ, попытка понять, что с ним происходит, принять то или иное решение, например:

Новый период жизни начинается. Зачем же волнуете вы снова мое сердце, обманчивые видения молодых лет? Зачем возникают снова передо мною прежние сомнения, старинные вопросы, давно разрешенные суровым рассудком зрелого возраста?25

Смысл этих вопросов - выбор жизненного пути, типа поведения, в конечном итоге - осознание своего места в мире.

\footnotetext{
${ }^{23}$ Ф. М. Достоевский, Двойник..., с. 147.

${ }^{24}$ Там же, с. 169.

${ }^{25}$ Н. Д. Ахшарумов, Двойник..., с. 6.
} 
Прошлое героя повести Ахшарумова (здесь есть временная ретроспекция) отделено от его настоящего промежутком всего в три года, но за этот период жизни Алексей Петрович принципиально меняется. Три года назад он жил как типичный разночинец, занимался литературой, писал пьесы, которые ставили в театрах. Однако в момент, к которому относятся события его сегодняшней жизни, Алексей Петрович принял решение не отвлекаться на литературу, служить, создать семью, иначе говоря, устроить свою жизнь разумно и надежно: «[...] я много хлопотал,- отмечает он в дневнике, - и место в частной конторе уже очистилось» ${ }^{26}$. Теперь он уже имеет приличную квартиру, хорошо одет; за него готовы с радостью отдать замуж девушку из приличного дома.

Перемены, с ним произошедшие, он отчетливо сознает сам, понимая, что его нынешнее положение связано не только с приобретениями, но и потерями:

Да, ... надо признаться, я был тогда счастлив, я весело жил! Двадцать пять лет, молодое здоровье, влюбленное сердце, карман..., правда, иногда пустой по целым неделям; но зато какой восторг, когда звенел в нем подчас кошелек, туго набитый целковыми и ассигнациями! Жизнь не шла у меня тогда, как теперь у меня это часто бывает, размеренным, заученным ходом, а завтра не было похоже на вчера.

Какая пестрота! какое разнообразие! Сегодня модное платье с иголочки и обед в самом лучшем отеле, рейнвей и шампанское, и дорогие сигары, и театр после обеда; а завтра... скромный чай с сухарями, да трубка простого русского табака. Сидишь себе целый день на своем чердаке, в старом халате, зарывшись по шею в тетради и книги, или просто валяешься на диване с каким-нибудь романом Поль де Кока, взятым напрокат из книжной лавки ${ }^{27}$.

Постоянная рефлексия героя материализуется в образе его двойника, хотя формально его появление мотивировано вмешательством доктора. Двойник объясняет Алексею Петровичу суть произошедшей катастрофы: то лучшее, что было в нем, оказалось вытеснено экспериментом Морица, воплотилось в двойнике, который пытается воззвать к голосу сердца и чувству чести Алексея Петровича.

Герой Ахшарумова похож на своего двойника, но тот выглядит более болезненным, одет в его старую шинель. Двойник Алексея Петровича появляется перед ним несколько раз и постоянно напоминает ему об их неразрывной связи:

Я знаю, - продолжал он через несколько минут: - мне суждено погибнуть в тяжелой, медленной пытке; но не думай и ты жить спокойно. Покуда я жив, я тебя не оставлю.

\footnotetext{
26 Там же, с. 40.

27 Там же, с. 12.
} 
Я буду смущать твои радости, буду являться перед тобой, и ты не думай уйти! От меня не убежишь и не спрячешься... Я везде, везде за тобою... - Он протягивал свои исхудалые руки, он хватал меня за шинель..., но страх дал мне новую силу, я отскочил в сторону и опять пустился бежать ${ }^{28}$.

Все разговоры Алексея Петровича с двойником - это спор, попытка доказать свою правоту и порядочность. Однако двойник, будучи, по сути, его внутренним голосом, его «лучшим» я, оказывается чрезвычайно проницателен. Он постоянно объясняет Алексею Петровичу, что с ним происходит, например:

Боже мой! Боже мой! - говорил он, поднимая глаза и руки к небу. - Как скоро и как жестоко забыто все старое! Как трудно разбудить в застывшей душе его хоть одну бледную тень того, чему прежде поклонялась она так усердно и пламенно!.. Ничего! Ничего!.. Как?.. и эти книги в шкафу, этот письменный стол с черным портфелем, они ничего вам не напоминают?.. Этот портрет на стене - он ничего не говорит? Они не говорят вам, что есть в жизни роскошь лучше мягких диванов и легкой кареты; есть стремленья - хотя бы, например, любовь к науке, жарче желудочного аппетита и благороднее того, что вы зовете честолюбием? ${ }^{29}$

Борясь с ним, герой Ахшарумова борется со своей совестью и одновременно со своим прошлым.

Убеждая себя в преимуществах своей нынешней жизни, Алексей Петрович вынужден либо оправдываться перед двойником, либо нападать на него с упреками. Так, в ответ на слова героя о том, что его жалование будет составлять «две тысячи целковых, чистого правильного дохода» ${ }^{30}$, двойник замечает: «Прекрасно, да вот беда! Ну, что если правильного не хватит? Тогда, может быть, придется...»³1. И хотя он не договаривает, Алексей Петрович понимает, что речь идет о взятках и с чувством искреннего негодования отвергает это предположение. Двойник весьма прозаически разъясняет ему рациональные причины его будущей женитьбы (красивая женщина, хозяйка в доме и т.д.). Мотив выгодной женитьбы не занимает в повести Ахшарумова главного места, но факультативно присутствует - в попутных замечаниях героя: «Кроме того, Софья Васильевна имеет приданое» ${ }^{32}$; «Нет, не очень большое, но все-таки больше, чем я ожидал. Тридцать тысяч чистыми деньгами, в Коммерческом банке» ${ }^{33}$. Точно так же хладнокровно и проницательно двойник говорит Алексею Петровичу

\footnotetext{
${ }^{28}$ Там же, с. 36 .

29 Там же, с. 43.

30 Там же, с. 40.

31 Там же.

32 Там же.

33 Там же.
} 
о будущей службе: «Но подумали ли вы о доходном месте?» ${ }^{34}$ - словосочетание, которое позднее будет использовано Островским (1856), и после него станет восприниматься как прецедентный текст. При очередной встрече с героем, которая происходит возле дома, где живет Вера, двойник упрекает Алексея Петровича в том, что он, по существу, погубил Веру: оставил ее, несмотря на обещание жениться на ней.

Двойник постоянно предупреждает Алексея об опасности:

Я пришел к Вам еще раз напомнить: одумайтесь, пока есть еще время. Алексей Петрович! Вы идете по ложной дороге... Вы многое успели потерять с тех пор, как выгнали меня из своего сердца. Вы продали поэзию, любовь, вы, может быть, и честь свою решите продать! ${ }^{35}$

Наконец, не в силах справиться с охватившим его гневом, Алексей Петрович бросает в двойника чашкой, ранив ему лицо.

От встречи к встрече двойник выглядит все хуже и хуже:

Бледные черты лица имели в себе что-то мертвое, борода была не выбрита, волосы растрепаны, белье измято, платье и сапоги покрыты пылью, как у пешего странника, после длинной и трудной дороги: вся фигура носила вид какой-то усталости и вместе болезненного истощения ${ }^{36}$.

Последняя встреча с двойником происходит тогда, когда худшие опасения двойника сбываются. И потому его упреки оказываются для Алексея Петровича особенно невыносимыми. Двойник превращается в его беспощадного обвинителя:

Что ты сделал, - произнес он грозно; признавайся сию же минуту и не смей солгать ни полслова! Что ты сделал, предатель!

Я вспомнил о том, что я сделал, вспомнил и ассигнации, лежавшие у меня в кармане... В груди промелькнуло, как молния, чувство жгучего, невыносимого стыда; но это был миг... Все исчезло, гнев задушил во мне все остальное ${ }^{37}$.

Результат этого гнева - убийство двойника и охватившее Алексея Петровича чувство раскаяния и ужаса: «Убил! Убил! Твердил мне внутренний голос: убил лучшую половину души своей!» ${ }^{38}$.

Если двойник Голядкина в итоге одерживает победу и занимает место Голядкина-старшего, то двойник Алексея Петровича оказывается трагичес-

\footnotetext{
34 Там же.

35 Там же, с. 70.

36 Там же, с. 69.

37 Там же, с. 81 .

38 Там же, с. 82.
} 
ким лицом и жертвой. Таким образом, как сами герои, так и их двойники, отношения между ними у Достоевского и Ахшарумова являются прямо противоположными. Прямо противоположными оказываются отношения авторов к слову героев. У Достоевского оно диалогично, что сразу, уже в раннемтворчестве, определило одно изуникальных качеств его таланта. У Ахшарумова слово монологично, не вбирает в себя дополнительных смыслов, чужих голосов и сознаний. Все это не дает повода говорить о литературной полемике, ибо сама доминанта психологического анализа, тема двойничества, несомненно, сближает Ахшарумова с Достоевским. Скорее, речь идет о сложных внутренних связях писателей-современников, несомненном интересе Ахшарумова к творчеству раннего Достоевского, которое, очевидно, было воспринято им в контексте предшествующей русской и европейской литературной традиции. Возможно, в повести Ахшарумова есть и элемент скрытой полемики с Достоевским, свидетельствующий о неоднозначной природе литературной эволюции, предполагающий не только момент преемственности, но и, как показал Ю. Н. Тынянов ${ }^{39}$, полемику с предшественником.

\section{References}

Akhsharumov, Nikolay D. "Dvoynik”. Otechestvennye zapiski, № 3 (1850).

Bakhtin, Mikhail M. Problemy poetiki Dostoyevskogo. Moskva: Sovetskaya Rossiya, 1979.

Belinsky, Vissarion. G. Peterburgskiy sbornik. In: Polnoe sobranie sochineniy. Vol. 9. Moskva: AN SSSR, 1958.

Dostoyevsky, Fyodor M. Dvoynik. In: Polnoe sobranie sochineniy. Vol. 1. Leningrad: Nauka, 1972.

Druzhinin, Aleksandr V. "Pis'ma inogorodnego podpishchika v redaktsiyu «Sovremennika» o russkoy zhurnalistike (XII). Sovremennik. VI (1850): 192.

Evlampiyev, Igor' I. Povest' "Dvoynik” i metafizika „dvoynichestva” v tvorchestve F. M. Dostoyevskogo. Solov'yevskie issledovaniya, № (2) 26 (2010).

Fridlender Georgiy M. Dvoynik. Primechaniya. In: Dostoyevsky, Fyodor M. Polnoe sobranie sochineniy: v 30-ti tt. Vol. 26. Leningrad: Nauka, 1985: 229.

Lotman, Yuriy M. Simvolika Peterburga i problema semiotiki goroda. In: Izbrannye stat'i. Vol. 2. Tallin: Aleksandra 1922.

Nechaeva, Vera S. Ranniy Dostoyevsky. 1821-1849. Moskva: Nauka, 1979: 153-160.

Maykov, Valerian N. Nechto o russkoy literature v 1846 godu. In: Literaturnaya kritika. Leningrad, Khudozhestvennaya literatura, 1985.

Russkiye pisateli. 1800-1917. Biograficheskiy slovar', ed. P. A. Nikolaev. Vol.1. Moskva: Sovetskaya entsiklopediya, 1989: 129.

Toporov, Vladimir N. Peterburg i peterburgskiy tekst russkoy literatury. In: Mif. Ritual. Simvol. Obraz: Issledovaniya v oblasti mifopoeticheskogo: Izbrannoe. Moskva: Progress-Kultura, 1995: 259-367.

Tynyanov, Yuriy N. Literaturnyy fakt. In: Poetika. Istoriya literatury. Kino. Moskva: Nauka 1977: 258.

${ }^{39}$ См. об этом: Ю. Н. Тынянов, Литературный факт, [в:] он же, Поэтика. История литературы. Кино. Москва: Наука 1977, с. 258. 